\title{
COMMENTARY
}

\section{The marine microbial world: a voyage of discovery}

\author{
Susan Elizabeth Jones
}

The ISME Journal (2007) 1, 469-470; 2007; doi:10.1038/ ismej.2007.72

In the past decade, a series of remarkable advances have been made in the important and dynamic field of marine microbiology. To highlight this progress, Nature Reviews Microbiology has devoted its entire October 2007 issue to a collection of articles that focus on our current understanding of marine biodiversity, ecology and biogeochemistry. The context of the reviews contained in this special issue is described in this commentary.

The vast expanses of the oceans, together with lakes, rivers and ponds, provide most of the living space on Earth. A multitude of environmental niches are present in the oceans-some hot, some cold, some at the surface with yet more at high pressures in the depths. Indeed, some of the most extreme conditions for life can be found in the oceans. Microbiologists have long been interested in the phytoplankton, bacteria and viruses that dwell in the seas, and this interest dates back to the very first studies of Antonie van Leeuwenhoek in 1667, who first observed bacteria in numerous environments including seawater as 'very little animalcules'. Later, the influential biologist Claude Zobell, based at the Scripps Institutions of Oceanography, published a 240-page tome in 1946 titled Marine Microbiology (ZoBell, 1946) that laid the foundations for the modern field of marine microbiology.

Despite the undisputed and vital roles of marine microorganisms in the global ecosystem-driving biogeochemical cycles that affect climate and the cycling of elements and nutrients to other organisms-the marine environment remains woefully under-explored. In fact, until recently, the study of oceanic environments was hampered by significant technical hurdles. These included the difficulty of collecting representative samples from some of the more difficult-to-reach niches. For example, deepsea microbiology is relatively new because it is both difficult and expensive to recover material either from water many thousands of metres deep, or from beneath the seafloor.

Historically, marine microorganisms have been studied using traditional approaches, such as sampling, counting and isolating organisms into pure culture for laboratory-based studies. But the advent of fluorescent in situ hybridization followed by new techniques during the past decade, including massive and quick genome sequencing technologies, metagenomic approaches and novel culturing techniques have enabled microbiologists to study how marine microorganisms live, die and contribute to oceanic ecosystems far more effectively. For instance, the endeavours of $\mathrm{J}$ Craig Venter and colleagues in sequencing of DNA from the Sargasso Sea neatly revealed that proteorhodopsin, rather than chlorophyll, might be the main pigment that captures light in the marine environment (Venter et al., 2004). Other technical advances that have augmented the toolbox of microbial oceanographers include in situ ocean monitoring systems, robotic sample collectors and satellite imaging of planetary productivity. Key questions that marine microbiologists are asking today include how aquatic microbial communities assemble, function and interact; how aquatic microorganisms affect global processes including nutrient cycling and climate regulation; whether marine microorganisms offer an untapped resource of novel products; and how studying microorganisms in extreme oceanic environments might offer insights into the origins of life and the search for extraterrestrial life (DeLong et al., 2007).

Scientists are now beginning to move forward from cataloguing the life that is present in the oceans (although this remains an ongoing challenge) to more integrated approaches that include testing hypotheses about how organisms, and specifically microorganisms, in the seas function and interact, both with each other and their environment. In this new age of discovery in marine microbiology, interdisciplinary studies-combining the efforts of geologists, mechanical and software engineers, bioinformaticians, chemists, biochemists, climatologists and microbiologists-are an important mechanism to try and unravel essential planetary processes including climate, atmosphere and global nutrient cycling that take place in marine biomes. Understanding the contributions that microorganisms make to these processes has increasingly been recognized as implicit to advancing our knowledge of these crucial research areas.

The articles included in the Nature Reviews Microbiology Focus issue tackle several important 
themes. David Karl sets the scene by describing the recent advances in molecular ecology, metagenomics, remote sensing of microorganisms and ecological modelling that are revitalizing the field of microbial oceanography. Bo Barker Jørgensen and Antje Boetius review microbial abundance and carbon availability at the seafloor, in vent systems, in cold seeps and in the deep subsurface. They highlight how studying these habitats could result in a better understanding of the limits to life and the diversity of life on Earth. Farooq Azam and Francesca Malfatti outline the benefits of studying bacteria and archaea at scales relevant (nanometres to micrometres) to their adaptive biology, and how this could translate to oceanic processes occurring over kilometres. Mary Ann Moran and William Miller direct their attention to the carbon cycle in the coastal ocean and the bacteria that can cheat on a strictly heterotrophic lifestyle to derive energy from inorganic compounds or sunlight. They underline how activities of these bacteria might affect the retention of carbon in the marine food web and the exchange of climatically important gases between the ocean and atmosphere. Curtis Suttle describes how the most populous of the marine microorganisms, namely marine viruses, might shape microbial ocean communities. Viruses can exert large impacts on climate by lysing algae that form blooms in the ocean, leading to the release of dimethyl sulphide, a compound that stimulates cloud formation, thereby exerting a cooling influence on the climate. Paul Falkowski and Matthew Oliver argue that climate controls nutrient fluxes, which in turn determine cell size and distribution of phytoplankton populations. They draw on the phytoplankton fossil record to envisage the development of informed projections about how phytoplankton communities will change in the coming century. Even though wide-scale genomic efforts provide a window into the diversity of the microbial life that is present in the ocean, the importance of studying isolated organisms is undiminished. Ulrich Stingl and Stephen Giovannoni offer their perspectives on novel cultivation efforts and strategies, and examine the importance of this research.

Microbiologists are striving to explore the undiscovered territories of the oceans. With this focus on marine microbiology, the editorial team at Nature Reviews Microbiology invite you to join them on this fascinating voyage of discovery. Generous financial assistance, from the Gordon and Betty Moore foundation (http://www.moore.org/) and the Agouron Institute (http://www.agi.org/), has enabled us to bring these articles to our readers free to download. We hope that this collection stimulates interest, debate and new research in the microbial ecology of marine environments.

\section{SE Jones is at Nature Publishing Group, Nature Reviews Microbiology, London, UK E-mail: s.jones@nature.com}

\section{References}

DeLong E, Karl DM, Rocap G. (2007). Microbial oceanography. Challenges and opportunities. The Agouron Institute: http://www.agi.org/publications.html.

Venter JC, Remington K, Heidelberg JF, Halpern AL, Rusch D, Eisen JA et al. (2004). Environmental genome shotgun sequencing of the Sargasso Sea. Science 304: 66-74.

ZoBell CE. (1946). Marine Microbiology. Chronica Botanica Co: Waltham, MA, xv, 240pp. 